\title{
El conflicto de los modelos de evangelización para América Latina. Reflexiones a propósito de los 500 años
}

\author{
Leonardo Boff, \\ Petrópolis, Brasil.
}

1992 significa para los latinoamericanos una recha polémica. Están los que celebran los 500 años del descubrimiento y de la incorporación de las tierras descubierlas por los navegantes europeos a la cultura europea. Tienen la visión de aquellos que llegaron en las carabelas y desembarcaron el 12 de octubre de 1492 en La Espanola (hoy Santo Domingo). Para ellos con la fecha de los 50 n aftos, se celebra la dilazación de la fe y la expansión de los valores de la civilización occidental.

Están otros que denuncian la invasión y la conquista violenta con el consiguiente etnocidio en una proporción inimaginable (del orden de 25 indígenas muertos por cada sobreviviente). Es la perspectiva de los que estuvieron en las playas y fueron víctimas de la voracidad de los conquistadores. Los 500 años reviven una pesadilla. No aceptan esta fecha, pues América no fue descubierta. Ya existían desde hace más de 45,000 años. Esa fecha es de los dominadores que aquí continúan oprimiendo hasta el día de hoy. El recuerdo, por lo demás, de los 500 aflos es una buena oportunidad para hacer un balance de la lógica de la expansión colonialista europea y una crítica del espíritu expansionista y excluyente de la modemidad.

Hay todavía un tercer grupo que toma distancia de la celebración y de la denuncia y procura un cambio original. Es la oportunidad para que las culturas autóctonas hagan un autodescubrimiento, rescaten su propia identidad sofocada y planteen las exigencias de un diálogo profundo con la cultura europea y la religión cristiana. Son los de Abia-Yala, nombre que los indígenas Kunas de Panamá daban a lo que hoy denominamos América Latina y con el que significaban " tierra fecunda, tierra madura". 
Veamos sucintamente cada una de cstas posturas. ¿Qué significa para ellas "evangelización" y "nueva evangelización"? Aquí, más que en otros asunios, vale tener en cucnta el punto de vista de cada postura. En esta discusión se percibirá el acierto de la constalación: cada punto de vista es la vista desde un punto. No pretendemos permanecer neutrales en esta discusión. Queremos discutir cada punto a partir del cual se elabora el punto de vista. En una perspectiva de evangelización no todo punto de vista es legítimo. Motivos humanísticos, élicos y evangélicos nos ayudan a tomar una posición correcta.

\section{Evangelización como implantación y reproducción de un modelo}

En la investigación histórica concerniente a América Latina hoy es punto asentado que la conquista representa un momento de un concepto más amplio: el de la expansión comercial, políica y rcligiosa de las polencias europeas del siglo XVI. En encro de 1492, los reyes cabólicos de España expulsan de la península a los musulmanes. Unifican así el espacio político, religioso y cultural de Europa. En este octubre del mismo año Colón desembarca en tierras latinoamericanas. La mentalidad de conquista y de guerra se traslada para acá. Lo expresó bien, en 1552, Francisco López de Gomara: "Comenzaron las conquistas de los indios al acabar la de los moros, porque siempre los españoles guerean contra los in Tieles" (Hispanica victrix).

El móvil de la conquista es complejo. Son muchos los factores que empujaron a jos europeos a dejar ei Mediterraneo y lanzarse ai Aluántico, y preferir las rutas marítimas a las terrestres para llegar a las fuentes de la riqueza comercial. No es este o aquel factor el que determina la expansión. Es la totalidad compleja del orbis christianus, que posee una dimensión económica, polílica, ideológica y evidentemente también religiosa, y que se pone en movimiento de expansión y conquista.

Se conquista primero el espacio musulmán, y, después, siempre bajo las armas, la costa atlántica de Africa y las islas Canarias; finalmente, el vasto mar Océano. Al ser un movimiento global, reunía en un todo varios actores sociales del tiempo, junto con los colonizadores llegaban funcionarios, al lado de los plebeyos se incorporaban los nobles, criminales proscritos de la sociedad y proslitutas discriminadas se juntaban con hidalgos y doctores. Cada segmento tenía sus objetivos particulares que, no es raro, generaban conflictos cuando se encontraban en el mismo terreno de la colonia

La gran mayoria, si exceptuamos a los misioneros religiosos en los que constatamos un potencial fantástico de utopía y generosidad, buscaba cabalmente enriquecerse. Es paradigmática la respuesta de Francisco Pizarro, el destructor del imperio inca, a un misionero que le increpaba por no preocuparse por la evangelización y sí, excesivamente, por el oro: "No vine a eso, vine al oro". 
Es más, era cvidente para todos, y en esto no hay excepción ni en los mejores misioneros como B. de Las Casas o A. Vieira: América Latina debía agregarse a las costumbres político-culturales europeas e incorporarse a la fe cristiana. El orden cristiano era el único orden querido, concreta e históricamente, por Dios. Todos, desde los musulmanes, pasando por los indios y chinos hasta los indígenas más distantes de los rincones de los Andes, debían ser injertados a ese orden, por las buenas o por las malas. Fuera de él no había civilización (humanización) que mereciera tal nombre, salvación eterna posible. Las religiones autóctonas eran trampas de Satanás para dificultar la conversión. Debían ser destruidas.

Esta era la convicción de todos, desde los más facinerosos, como el general Pedro Alvarado que destruyó Tenochtitlán (ciudad de México), hasta los más santos de los misioneros, como el franciscano Toribio de Benavente, llamado por los aztecas "Motolinia" (el pobrecillo) por haberse identificado con los más pobres de los pobres indigenas.

Difícilmente en la historia de occidente encontraremos tanto etnocentrismo, dogmatismo, fundamentalismo y tolalitarismo como en las visiones de los europeos del siglo XVI. Esta rigidez cultural y religiosa está en la ralz del etnocidio y de la violencia aplicada sin miramientos contra indigenas y negros durante siglos y que perdura en el inconsciente colectivo y en los hábilos autoritarios de las clases dominantes latinoamericanas hasta los tiempos actuales. El propio Papa Pablo III, espantado, escribió una bula Sublimis Deus (1537) defendiendo a los indlgenas contra los "encomenderos" (hacendados que poseían indigenas a su servicio). Afirmaba de éstos que eran seres racionales, por tanto personas y no animales, como muchos creian, y que sus vidas y propiedades debian ser respetadas.

La conquista y la colonización constituyen en sí un acto de grandísima violencia. Implica que una nación con su cultura, memoria, historia y religión se somete a otra, que pierde su carácter de sujeto historico, que tiene que aceptar un bloqueo de su desarrollo autónomo, que debe adherirse a la lógica del otro, que debe asumir formas políticas, hábilos culturales y expresiones religiosas, y la misma lengua del dominador, que éste pasa a ser seflor de la vida y de la muerte de un pueblo entero.

Toda colonización desestructura la cultura sometida. Obliga a las personas a interiorizar la ligura del colonizador y a reprimir los legítimos reclamos de liberación y de justicia. Todos pasan por un terrible dilema o se someten al colonizador y entonces traicionan a sus antepasados y a sus hermanos y hermanas y así sobreviven como sujetos subalternos y dependientes, o bien resisten, se rebelan y son perseguidos, condenados a vivir en la clandestinidad o presos y muertos. Otros, para escapar al dilema, practican un refinado arte y técnica de someterse aparentemente y al mismo tiempo resistir y vivir su propia identidad 
bajo mil subterfugios y disfraces.

En esta situación conflictiva se desarrollarán los sectores dominados, como es el caso, por ejemplo, de los negros mulatos y pobres del Brasil, el fanoso jeitinho (maña), tan bien estudiado por el antropólogo Roberto da Matia'. Se trata de un "estilo de navegación social" mediante la cual se resuelve, de forma armoniosa, el conflicto entre la ley que prohibe y las situaciones personales que tienen sus exigencias. Esa habilidad es "cl arte de sobrevivir a las situaciones más diff́ciles". "un estilo de conciliar órdenes imposibles de cumplirse con siwaciones específicas, un modo ambiguo de burlar las leyes y las normas sociales más generales"'

A causa del proceso violento del sometimiento colonial los pueblos colonizados tienen una dificulcad enorme de claborar su identidad propia. Siempre están y se vieron obligados a mirarse en el espejo de otros. Y ese espejo llega distorsionado por todo tipo de prejuicios, que, interiorizados enseguida por el oprimido, hacen que éste pase a creer que él, por el hecho de ser indígena, negro, meslizo o pobre nada vale y que nació sólo para servir.

El mismo Hegel en sus "prelecciones sobre la filosofía de la historia" reproduce semejante prejuicio. Dice, por ejemplo: "De América y de su cultura, particularmente de México y del Perí, tenemos, si, conocimientos pero solamente aquellos que muestran que era una cultura natural, que debia desaparecer en la medida que llegase el espíritu; América so mostró y aún hoy se muestra física y espiriualmente impotente"4. El espíritu, como se echa de ver por el contexto, llegó por los europeos, portadores privilegiados del espíritu absoluto de la historia mundial.

A causa de tales ideas inculcadas, los colonizados se sienten pucblos divididos por dentro, históricamente trágicos. Muchas veces, después de sacudir el yugo, continúan dominados por las estructuras interiorizadas que les quitan la auto-estima, y que les llevan a mimetizar a los antiguos colonizadores y a soñar los sueños de ellos, en vez de proyectar sus propios sueños e intentar historizarlos.

Posiblemente el dato más dramático reside en el hecho de que los países colonizados, como los latinoamericanos, deben asumir el modo de pensar, de producir, de organizar el desarrollo según los moldes de los antiguos señores y no en consonancia con la lógica de las propias culturas autóctonas. De esta forma se alienaron y continúan alienados de las propias ralces culturales y de los motivos que les podrian traer autonomía y fclicidad.

La deuda externa actual de los países latinoamericanos (cerca de 300 billones de dólares) tiene antes un significado político que económico. No se pucde pagar, pero tiene como efecto mantener a los países amarrados al sistema del capical y a las políticas de los antiguos señores. 
En este contexto conflictivo, ¿que significa evangelización? Para decirlo en una palabra, la evangelización participó de la violencia del proceso global. No hubo el tal encuentro entre fe cristiana y cultura autóctona, sino el encontronazo, el choque cultural que desestructuró y hasta destruyó las culturas y las religiones. El cristianismo fue impuesto o por la dura violencia de las armas y del sometimiento (el pregón del "requerimiento", mediante el cual los indigenas tenian que aceptar la fe cristiana, al papa y al rey, daba lugar, en caso contrario, al uso de la violencia "legítima") o por la suave violencia de los "decimamientos" (sometimiento a tributación), los asentamientos o reducciones, las escuelas para los niños segregados de las familias, o las "doctrinas" y catequesis acopladas al aprendizaje de la lengua, de las costumbres europeas y al tipo de racionalidad europea (el tipo de catecismos que debían aprender de memoria).

Normalmente estos dos tipos de violencia, la dura y la suave, iban juntas, como aconsejaba el mayor teónico de las misiones del siglo XVI en la colonia, el P. José Acostas: "es necesario que vayan juntos el soldado y el sacerdote" "modo de anunciar el evangelio es el del misionero, rodeado de soldados y de aparato vario"n.

El miedo está en la base de la evangelización. No sin razón se hace la apología del miedo, como la gran arma por la cual los indígenas se convierten con más facilidad y eficacia. Se inculca el miedo de los castigos en el presente y el miedo de los castigos en la eternidad. Bien lo decía un colono español del siglo XVI: "La voz del evangelio se escucha solamente allí donde los indios escuchan también el estruendo de las armas de fuego".

Los propios indígenas, con frecuencia, se quejan lastimosamente. "Ellos nos enseftaron el miedo. Vinieron a marchilar las flores. Para que viviese su flor dafiaron y devoraron nuestra flor"' . La evangelización, en vez de ser realización de la buena-nueva, en la perspectiva de los indígenas colonizados pasa a ser seffal-de-tristeza. “'Ay! Apenémonos porque llegaron... Entre nosotros se introdujo la tristeza, entre nosotros se introdujo el cristianismo"n.

Retomando la cuestión: ¿qué significó entonces evangelización en contexto de conquista y de colonización? Significó, en primer lugar, la implantación de la totalidad europea, de la lengua, de la cultura, de los modos de producción, de organización familiar y política y de la visión del mundo. Junto a esta totalidad venía, paralelamente, la implantación y reproducción del cristianismo cuyo modelo estaba construido en Europa, en la doctrina dogmática, en la celebración litúrgica, en la codificación moral, en la devoción a los santos y en la forma de significar religiosamente lo cotidiano.

Prácticamente no hubo en la cristianidad colonial creatividad alguna significativa porque no se dio el encuentro necesario entre fe cristiana y los valores culturales presentes. Los misioneros franciscanos que en los origenes intentaron crear una Iglesia de la Indias fueron aislados y fracasaron. No se permitió a las 
variadas naciones indígenas que hicieran su asimilación de la tradición judeocristiana y la síntesis europea a partir de sus propias matrices indígenas.

Los indígenas, en sentido estricto, no fueron evangelizados. Hubo ensayos defectuosos de evangelización. Fueron forzadamente incorporados e insertos en la totalidad romano-católica, en la parte ibérica de América, Latina, o en la protestante, en las regiones del Caribe.

No eran libres para aceptar o rechazar a partir de sus tradiciones religiosas el mensaje cristiano o entrar en un diálogo mutuamente fecundo con el mismo. El famoso Coloquio de los doce apóstoles franciscanos con los sabios aztecas, en 1524, fue un inmenso des-encuentro y fracaso. La rigidez romano-calólica que llevaban consigo les impedía vislumbrar algún valor en la religión de los aztecas. El efecto fue la satanización de las religiones de los mismos y la imposición del cristianismo en un inmenso proceso de sustitución y de inculcación.

Este proceso se dio en el marco del patronato, es decir, de la alianza entre el poder religioso y el poder político que creo la cristianidad europea, trasplantada ahora simplemente hasta aquí. El poder político siempre detentó el uso legítimo de la violencia y de la coerción. Y fue usado para la implantación del cristianismo.

¿Puede una evangelización conservar su estatuto teológico de evangelización cuando se utiliza la coerción? Toda la tradición cristiana, aun la más conservadora, responde negativamente. Sin embargo, esta fue la lógıca dominante de la evangelización en los tres primeros siglos de la presencia cristiana en América Latina: la imposición del cristianismo como parte de la totalidad colonial y de la cultura dominante de los colonizadores.

No obstante las contradicciones de este fenómeno de implantación y reproducción del modelo cristiano europeo, acaeció, a su pesar, un fenómeno de gran relevancia. Este tiene que ver con la marha, la habilidad a la que hacíamos referencia anteriormente. Los colonizadores pobres se relacionaron con la población autóctona. Se mezclaron no solamente las razas, sino también las creencias. Esos cristianos eran más portadores de un cristaanismo medieval, caracterizado por las devociones a los santos, por las romerias, mandas y promesas de la propiedad familiar, que representantes del cristianismo polémico y celoso de la ortodoxia de la contra-reforma. Este cristianismo medieval se sincretizó con elementos de la cultura indigena, negra, mestiza y oficial. Dio origen al catolicismo popular, tal vez la creación cultural más original y rica del experimento religioso latinoamericano. Gracias al mismo, los pobres, los colonizados, los esclavos, los indígenas y los mertizos encontraban fuerza para soportar la miseria de la vida y un sentido mínımo dentro de los mecanismos de opresión que eran extremadamente deshumanizadores.

¿Qué significa actualmente la nueva evangelización para aquellos que exal- 
tan la conquista y magnifican la venida del evangelio (a pesar de las contradicciones) a América Latina? Para responder a esta pregunta debemos considerar el hecho siguiente: existen hoy en la sociedad latinoamericana sectores articulados con grupos europeos (entre ellos los de las antiguas potencias coloniales) que políticamente quieren mantener a toda costa a América Latina dentro del orden de occidente. Esto implica la asunción del cuadro político, de las instituciones y de los valores que constituyen el ethos occidental.

Quieren una América Latina desarrollada, pero dentro del marco del capitalismo que deberá, naturalmente, ser moderno, civilizado y generador de abundancia de bienes. No ven con buenos ojos los movimientos libertarios que emergen de una conciencia de autonomía y de rescate de los valores culturales autóctonos y de los elementos de resistencia y de liberación que se fueron acumulando en 500 aflos de vida política y social latinoamericana.

En el fondo de este pensamiento está cambién la concepción de la nueva evangelización. Se quiere un cristianismo fuere, pero dependiente de Europa y de las líneas trazadas por la administración central del Vaticano. El proyecto colonial, evidentemente sin usar ese nombre, debe prolongarse en su matriz y ser depurado en sus avatares. Por ello, toda creatividad doctrinal, litúrgica y pastoral se coloca bajo sospecha de violar la unidad necesaria con el modelo romano católico. Las características de la romanidad deben mantenerse y deben ser reconocibles en todo lo que se emprende de importancia en la vida de la Iglesia. Será punto de iủentíficación de su autenticidad en cualquier iniciativa y expresión de unidad católica.

Se ha de procurar mantener la misma alianza con el poder. La evangelización se hará con poder y en asociación con los que detentan el poder. Hoy no será ya el Estado (aunque lodavía en Argentina, Colombia y outos países latinoamericanos se mantiene el esquema de cristiandad por los concordatos con los gobiemos), sino con otras fuerzas sociales hegemónicas. La alianza se hará con agentes del poder social y cultural extraídos de las clases medias y de los profesionales liberales de las empresas nacionales y transnacionales. Son los hijos transnacionalizados de la modemidad. Ellos son los que llevarán adelante el proyecto de la nueva evangelización a otras clases sociales, especialmente a las mayorlas poores. Se niega a éstas el camino de la liberación, pues esto supone una ruptura con el siaius quo tradicional y la valorización de un nuevo sujeto histórico, el pueblo organizado y las clases populares con su cultura y sus valores, también los religiosos. Tal proyecto es descalificado como manxista, violento, antirreligioso y ajeno a la tradición latinoamericana.

Esta visión está explícilamente presente en los textos preparatorios de la IV Asamblea Plenaria del CELAM, en Santo Domingo, en 1992. De nueva, en verdad, esta evangelización no tiene nada. Mantiene el mismo proyecto de sociedad. Prolonga el mismo modelo de Iglesia de neo-cristianidad curopea, ro- 
mana, clerical y articulada con los poderes sociales dominantes. No innova en nada el método de evangelización. El sujeto de la evangelización es la institución eclesial apoyada por los agentes del poder social y no en los fieles y en las nuevas formas de eclesialidad que en ellos se están formando, sólo que en lugar de carabelas se usan hoy los satélites de comunicación, a lo que aspira el proyecto de "evangelización o Lumen 2000".

El efecto es siempre el mismo: repetición en vez de recreación. Una copia más de lo mismo en lugar de la génesis de algo nuevo que merezca el nombre de evangelización. El cristianismo no tiene créditos en el código de experiencia larinoamericana, sino que continúa siendo la reproducción del cristianismo europeo que se alimenta de las fuentes típicas de la cultura occidental europea. Vale recordar que las culturas-testimonio latinoamericanas no son occidentales, ni la cultura del silencio de las grandes mayorías oprimidas se rige por la lógica cartesiana. Son otra cosa. Poseen otros matrices y valores a partir de los cuales sería posible una nueva inculturación de la fe cristiana, dando origen a un ensayo original del cristianismo en esta parte del mundo.

¿Dios no querrá ser alabado y servido en lengua quechua, tupiguarani o yanomani? ¿No significa la lengua una forma singular de afirmación del mundo? ¿No agradará a Dios ser pensado, afirmado y celebrado en las más variadas lenguas? ¿No apreciará las danzas y los ritos afro-americanos? ¿No se alegrará con los grandes suetios y mitos de los xavantes o de los krain-akarore? ¿Por qué éstos deben hacerse otros, dejar de ser lo que son, para aproximarse a aquel Dios que en su hijo Jesús tanto se aproximó a la came humana? Estas cuestiones no reciben respuesta por parte de la evangelización reproductora.

\section{Evangelización como proceso de liberación integral}

La segunda perspectiva es la representada por los que sufrieron la llegada de los europeos como invasión y conquista con toda la violencia que la misma comportó. Las poblaciones autóctonas sufrieron un trauma del que aún no se recuperan hasta nuestros dlas. Los testimonios de sus sufrimientos fueron recogidos por historiadores serios como Miguel Leon Portilla ${ }^{10}$, Nathan Wachtel" $y$ recientemente por Eduardo Galeano ${ }^{12}$.

Inicialmente, los indigenas de las playas acogieron con gran benevolencia a los europeos de las carabelas: "Hasta nos consideraron como dioses". Tanto en el imperio azteca como en el inca existía el mito del dios civilizador. Después de realizar su obra humanitaria, Quetzacoad en México y Viracocha en el Perú habian desaparecido por el mar, peró volverían un día, del oriente, para traer la suprema realización civilizadora. Las profecías indicaban fechas y seftales. Sucedió que, no sabemos por qué perversa falalidad, aquéllas coincidian con la llegada desde oriente de los hombres de barba rubia, sobre un extrafío animal (el caballo), más o menos en las fechas previstas, en "la era del chakal", en México, 
en el reinado XII ${ }^{\mathbf{Q}}$ inca (Alahualpa), cn el Perú.

Moctezuma, sobcrano azteca, dice cortésmente a Hemán Cortés al llegar a la ciudad de México, el día 8 de novicmbre de 1519: "Señor nuestro... has llegado a tu ciudad, México. Has llegado aquí para sentarte en tu solio, en tu trono... Esto era lo que nos habían dejado dicho los reyes, los que rigieron y gobernaron esta tu ciudad: que te instalarías en tu asiento, en tu lugar, que habrias de venir hasta aquí. Pues ahora se realizó: ya llegaste, con harta fatiga, con trabajo has venido. Acércate a la tierra: ven y descansa; toma posesión de tus casas reales; da refrigerio a tu cuerpo. Vengan a su tierra, señores nuestros"'13.

En el Perú, los conquistadores son descritos por la relación de Titu Cusi Yupanqui como "viracochas, que es el nombre con que nosotros denominábamos antiguamente el creador de lodas las cosas"; sus arcabuces eran vistos como truenos del cielo's.

La decepción llegó pronto. La sed de oro y plata los hacia cometer barbaridades. Como conficsa Moctezuma, los españoles "todo agarraban, de todo se apropiaban, Lodo arrebataban como suyo"'s. El rigor del sometimiento, las gueras, la incidencia de enfermedades nuevas para las que los indigenas no tenían anticuerpos (gripe, sarampión, varicela, tuberculosis, sífilis) reducirán drásticamente la población. En cuatro siglos se redujo a un octavo de la original, que era de ccrca de 50 millones.

Drámatica es la descripción azteca de la destrucción, conservada en el anónimo de Tlatelolco: "En nuestros caminos yacen dardos quebrados; cabelleras esparcidas; destruidas las casas, humeantes sus muros, gusanos abundan por calles y plazas y las parcdes están manchadas de sesos reventados; las aguas corren rojas como si alguien las hubiera teñido ${ }^{-16}$.

No causa admiración que al final del Coloquio de los misioneros franciscanos con los sabios, éstos terminen con esta lamentación terrible "déjennos pues morir, déjennos perecer, pues nuestros dioses ya están muertos"17. Cuando los propios dioses ya están muertos, no hay ya razón alguna para seguir viviendo.

En una sola palabra expresaron los mayas la consecuencia funesta de la conquista: " $i$ Castrar el sol! Para eso llegaron estos extranjeros" divinidad suprema, la fuente de la vida del universo, el sentido de lodas las cosas. Intentar destruir tal significado fue la atrocidad de la conquista en la perspectiva de las víctimas.

Este proceso de invasión y sometimiento por la violencia, dura o suave, no ocurrió sólo al comienzo, en los inicios del siglo XVI, sino que sentó la lógica de las relaciones entre las potencias colonizadoras y los espacios ocupados en los siglos siguientes. Será siempre una relación desigual, de dependencia y de reproducción de lo que ocurre en las metropolis. 
Se produce y se comercializa fundamentalmente lo que interesa a los centros metropolitanos. Se establecen, con preferencia, formas políticas que convienen a los intereses de las potencias hegemónicas (prefieren gobiemos duros que garanticen suficientemente el orden para que el capital haga sus negocios). Predominan aquellas ideas y aquellos gustos artísticos que surgen primero y se afirman en los paises centrales.

Por más que se discula la teoria de la dependencia para caracterizar las sociedades que un día fueron colonizadas, hay un dato irrefutable: el hecho de la dependencia de los países latinoamericanos con referencia a las decisiones que los paises opulentos toman acerca del destino del mundo y del tipo de inserción de las distintas regiones en la política mundial. Innegablemente hay un centro y una inmensa periferia. Este hecho, a partir del cual se elabora la teoría, seguramente no explica todo el complejo fenómeno del atraso tecnológico y la fragilidad de nuestras instituciones políticas, pero es un factor determinante, aunque no exclusivo, de nuestra situación actual.

El hecho mayor es que no tenemos en nuestras manos las fuerzas y los medios para diseffar nuestro destino. Estamos siempre enganchados a un destino más abarcador que deciden otros por nosotros, sin nucstra participación, y al que nos debemos sumar. Somos un inmenso proletariado externo de los paises del mundo opulento y explotador. De esta suerte constituimos, en los trazos fundamentales, una realidad-espejo y no una realidad-fuente.

Desde el inicio fuimos condenados a existir y a producir para ouros. No nos fue permitido tener una existencia en sí y para nosotros con una producción adecuada a los medios de producción de nuestra cultura y para el consumo de nuestro mercado interno. Antiguamente exportábanos materias primas naturales, enseguida materias semifacturadas, después manufacturas, y hoy directamente capital. Es el nuevo tributo que pagamos a los modemos sehores para que podamos continuar produciendo lo que nosotros mismos no podemos consumir dentro del sistema impuesto por ellos.

Siempre que hay un poder opresor, surge también una resistencia al mismo y un antipoder. Los 500 años de sometimiento están marcados por rebeliones de indios, por intentos de liberación de los negros y por mil formas de resistencia de los oprimidos. Todos estos intentos fueron frustrados con violencia Las clases dirigentes rara vez mostraron cordialidad, sino dureza y desprecio por el pueblo, por su cultura, su lengua y su religión. Aliadas a los poderes transnacionales, son aquí los representantes del gerente ausente; se mancomunan en los mismos intereses y mantienen un foso abismal entre ellas y el pueblo.

A la opresión debe suceder, como contrapartida, la liberación. Este anhelo siempre fermentó sueflos, resistencias y luchas a lo largo de los 500 afios, más particularmente a partir de los afios $\mathbf{6 0}$ cuando tomó cuerpo en múltiples movi- 
mientos populares, políticos, intelectuales y religiosos. Especialmente irtumpió en el suefio de varias naciones indígenas, en los gnupos afro-launoamericanos, en los movimientos de mujeres, de los sin-tierra y de los pobres en general. Todos ellos quieren ser sujelos de su hisloria y no objeto de la benevolencia ajena que los mantiene dependientes o sujecos secundarios de una historia que no les permite moldearse con caracteristicas propias.

Estos grupos conocen la función política y económica que la deuda externa representa para mantener a nuestras naciones en relación de dependencia. Pcro han concientizado también otro tipo de deuda, las varias deudas que Europa contrajo con América Latina y que no ha pagado hasta el día de hoy. Esto nos confiere un sentido de justicia y de reivindicación de una reparación siempre negada. De deudores financieros pasamos a acreedores, por diversos títulos, de las antiguas potencias coloniales.

En primer lugar, hay una pesada deuda histórico-éınico-cultural. Los europeos desarticularon y. en parte, destruyeron las grandes culturas- testimonio de América Latina. Diezmaron la población autóctona. Destruyeron el modo de producción de la mayoría de los pucblos, que era comunitario y participativo. Sofocaron los grandes milos y uadiciones orales. Liquidaron la memoria colectiva a parir de la cual los pueblos extraían el sentido a su vivir. Impidieron una historia autónoma, hecha según la lógica de las propias culturas. Se les negó a las poblaciones ser sujetos, tuvieron que acomodarse dentro de la historia de otro - que era opresor- y tuvieron que incorporar sus simbolos y mimeuzar sus valores. Fueron forzados a sentirse y aceptarse como extranjeros en su propia tierra.

La elegía anónima que un quechua escribió en homenaje al inca Alahualpa, asesinado por los hombres de Francisco Pizarro, revela esta destrucción de identidad que, en gran parte, perdura hasta nuestros dias: "Bajo imperio extranjero, abrumados de martirios y destruidos, perplejos, extraviados, sin memoria, solos; estamos delirando; nuestra errante vida dispersa, rodeada de peligros sin cuento, en manos ajenas entregada"19.

Perdura todavfa la deuda ecológica de Europa con América Latina. La invasión del continente provocó estragos irrecuperables en la explotación de las riquezas naturales, en la utilización del suelo y en la inmensa deforestación. Se implanto un estilo de desarrollo y de racionalidad de trabajo que implica una agresión sistemática de la naturaleza y un irrespeto a sus ciclos naturales. Este desarrollo aquí, en condiciones de dependencia y de asociación al desarrollo de los parses ricos, se presenta profundamente desigual, generador de exclusiones y extremadamente injusto. La injusticia social está en la raíz de la injusticia ecologica que se verifica en las grandes ciudades latinoamericanas y en los medios pobres del campo. 
En fin, hay aún una deuda de evangelización auténtica e integral. Ya apuntamos antes cómo la evangelización fue soportada por las poblaciones como parte religiosa del proceso de dominación militar, política y cultural. El maya Chilam Balam de Dumayel, ya bajo influencia cristiana, lodavía en el siglo XVI escribió irónicamente: "Los muy cristianos llegaron aqui con el verdadero Dios; pero aquello fue el comienzo de nuestra miseria... el principio de nuestro sufrimiento... Ese Dios verdadero que viene del cielo sólo de pecado hablará, sólo de pecado será su enseñanza'zo.

Por tanto, la evangelización no era liberadora. El evangelio llegó a América Latina distorsionado por la injusticia, reducido por los intereses sin excusa de la cultura europea, desnaturalizado porque sirvió de insurumento y sujeción y muerte, y no de promoción de vida y de libertad.

Desconocer esta desfiguración del proceso evangelizador latinoamericano, acaecido bajo el signo de la colonización, es hacerse insensibles a la memoria de millones que fueron vícumas de los colonizadores. En lo hondo es mostrarse inhumano y sin piedad, actitudes que no se compaginan con el evangelio y la práctica de Jesús.

Algunos discursos oficiales de cierlos sectores del Vaticano y de algunos episcopados latinoamericanos, particularmente de segmentos importantes del CELAM, escamotean esta verdad. Siguen como rehenes de un discurso triunfalista y, en el fondn, cmel para las culturas avasalladas. Contra la verdad y la justicia siguen reproduciendo mensajes sin suficiente autocrítica, queriendo reafirmar a la Iglesia como institución y disculpar a la empresa misionera de los desmanes cometidos contra poblaciones indefensas y llenas de apertura evangélica, como la confirman tantos testimonios del siglo XVI.

Es obra del espíritu de Dios el hecho de que los obispos, profundizando y completando la tradición de los misioneros proféticos de la historia latinoamericana, hayan hecho en Medellin (1968) y en Puebla (1979) una histórica opción por los pobres contra la pobreza y en pro de su liberación. Proyectaron una evangelización desde la perspectiva de las víctimas y por eso esa evangelización se presenta como liberadora. "El mejor servicio al hermano es la evangelización que lo dispone a realizarse como hijo de Dios, lo libera de las injusticias y lo promueve integralmente ${ }^{m 21}$.

En esta perspectiva, el pobre emerge como sujeto de su liberación y también de la nueva evangelización. El es el sujeto creador de la lglesia. Las comunidades eclesiales de base representan la obra de los propios oprimidos, que apoyados por tantos obispos, sacerdotes, té́logos y otros agentes sociales, a parir de su fe y de su cultura, están recreando una Iglesia como comunidad de vida, de funciones y de servicios. De ahí emerge un modelo eclesial más cercano al suefio de Jesús y de los apóstoles, comunional, participativo, popular y abierto a 
otras formas de organizar la comunidad cristiana, sea en la tradición católica, sea en la ecuménica.

Solamente en esta visión liberadora se puede hablar de nueva evangelización. Sólo ella rompe con la melodología del pasado, quiebra el cautiverio bajo el cual la lglesia y el evangelio venían siendo sometidos por el poder dominante que impedía mostrar su potencial intrínseco de liberación.

En el cristianismo popular, en las comunidades eclesiales de base y en las variadas pastorales sociales se crean condiciones adecuadas para la inculturación del mensaje cristiano. De ahı ya estŕ surgiendo un rostro nuevo del cristianismo con la colaboración de todas la razas y de todos los mestizajes que se dan aquí. Ya no es, ciertamente, un catolicismo sólo romano, aunque tenga sincretizado elementos del mismo en su síntesis, pero es un cristianismo auténtico, latinoamericano, amerindio, afroamericano, mestizo, blanco y ecuménico. Las iglesias, que fueron cómplices en la dominación, están siendo ampliamente solidarias en la liberación.

\section{Evangelización como autonomización de las culturas y recíproco apren- dizaje.}

La tercera postura procura situarse más allá de los "celebradores o de los anticelebradores" de los 500 años. En varios encuentros de líderes indigenas del continente se llega a una línea más o menos común ${ }^{2}$. Es importante aprovechar la movilización de la opinión pública, de los estados, de las iglesias y de los varios saberes para proceder a un autodescubrimiento de la liberación y de los valores de las culturas autóctonas.

El saqueo del oro y de las riquezas naturales perpetrado por los conquistadores no es casi nada en comparación con los secuestros de la identidad y de la memoria historica que sufrieron las culturas indígenas. Se mutiló al hombre originario, su sabiduría, su ciencia, sus religiones y su sentido comunitario. Ahora se presenta una ocasión única para recuperar la historia anterior al 1492. No en el sentido de los arqueblogos y de los etnohistoriadores, sino en la perspectiva de los propios indrgenas que valoran la memoria aún viva del pasado.

En primer lugar, es decisivo rescatar la sabiduría de los antepasados, es decir, los motivos y el sentido de la vida que informaron las culturas antiguas. Esa sabiduría está presente en lo imaginario, en los dichos, en los mitos, en los ritos, en las fiestas, en los hábitos familiares y en los modos de trabajar que subsisten a pesar del predominio de la cultura de los invasores. Es una cultura de lo oral y de los lugares sagrados (montafias, valles, ríos y la propia tierra venerada como Pachamama, la gran Madre). Los milos aquí no se deben entender en la perspectiva de la discusión moderna europea, provocada por el proyecto de Bultunann, de desmitologización y reinterpretación de las Escrituras. 
Mito equivale a la propia vida en cuanto es fuerza que sustenta y hace mover al pueblo a través de símbolos poderosos, de sueños, de proyectos y de visiones. Son los grandes ideales de libertad, de reintegración de la tierra robada, del trabajo comunitario, del respeto y veneración de la naturaleza, de vivencia distinta del trabajo. Este no es, como en la mentalidad modema, la fuerza de producción de bienes. Para los indígenas es una colaboración que el ser humano da a la gran Madre Tierra, puesto que ella produce todo y todo preve. La tierra no es, como para el hombre occidental, un medio de producción, sino una prolongación del propio cuerpo humano vivo, una realidad con características divinas. Por esto es venerable y el ser humano vive con clla una profunda unión mística.

Lugar especial en este proceso de rescate ocupa la religión. Esta fue negada por los misioneros o folclorizada por la cultura dominante. Ahora se hace necesario reconocer su validez y legitimidad. No es sin más un dato axial de la cultura. Más importante es aún su significado estrictamente teológico.

Dios no llegó aquí con los misioneros. Ya estaba presente en las culturas. La revelación no se restringe a la experiencia judeo-cristiana, recogida, como norma, en las Escrituras, sino que es un dato permanente de la salvación universal, pues el Dios-comunión se autodona continuamente en gracia y perdón a todos los seres humanos en todos los momentos de la historia. Las religiones son ya una respuesta que da todo un pucblo, colectivamente, a la propucsta de Dios. Por esto, a través de las religiones, Dios siempre visitó a su pueblo y el pucblo se encontró con su Dios.

Esta comprensión produjo una teología cuyo sujeto es su propia comunidad indígena, enraizada en la tierra y en la memoria de los ancestros. Está abierta a todos, a otros pobres, especialmente a los negros que sufrieron más en América Latina.

Mencionemos ahora algunas conclusiones del seminario latinoamericano de teología india, celebrado en México, del 17 al 22 de septiembre de 1990, pues en ellas se ve la dirección en que se viene articulando esta reflexión. "Nos proponemos profundizar y consolidar nuestras teologías indias e ir descubriendo sus esquemas y métodos propios para un diálogo de profundo respeto con las leologias cristianas y no cristianas; relecr la Biblia como una de las herramientas que amplian nuestra reflexión teológica, reconociendo que Dios se revela en lodas las culturas; en la óptica de nuestras teologías indias, el diálogo con las teologfas cristianas y no cristianas presupone el despojarse de absolutismos y privilegios para que este diálogo nos lleve a un verdadero enriquecimiento mutuo; la contribución cristiana debe traducirse en actitudes y voces proféticas, para que el diálogo entre las teologías se ponga al servicio de la justicia, de la vida y de la liberación"z?.

Esta reflexión insiste en el hecho de que los indígenas no son pobres, sin más, y por ello deben ser apoyados en sus luchas. No les agrada ser mirados

Digitalizado por Biblioteca "P. Florentino Idoate, S.J."

Universidad Centroamericana José Simeón Cañas 
como pobres, porque culturalmente no lo son. Son distintos y diferentes en su cultura y en su religión, ricos en grandes valores personales y comunitarios. Tal diferencia precisa ser recibida y valorada como algo grande que revela a Dios y como formas distintas de realización del misterio humano. Aunque técnicamente los indigenas estén poco desarrollados, culturalmente, sin embargo, son sofisticados y profundos. Han conseguido una integración del ser humano con la naturaleza, un equilibrio entre el trabajo y la actividad, una solidaridad generacional y un sentido que, no raramente, nos dan a los occidentales lecciones de sabiduria.

Lo que se dice de los indígenas de igual modo y aún más vale para las religiones afroamericanas de América Latina. Los negros esclavizados tuvieron que asumir el cristianismo de sus señores, los colonizadores blancos. ¿Qué evangelio pucde anunciar el lobo a sus ovejas? ¿Un señor de esclavos a sus esclavizados? Jamás será un evangclio que hable de liberación, pues sería negarse a sí mismo, sino que se verá obligado a hablar de sumisión y obediencia. Si hay liberación, sería necesariamente espiritualista, dislocada de la vida real. ¿Un evangelio sin libertad y sin liberación podrá ofrecer algún eco del evangelio de Jesús y de los apóstoles?

A pesar de las imposiciones de los dueños de esclavos, los negros supieron guardar bajo mil disfraces y mafias su propia religión. La sincretizaron con elementos de la cultura popular ambiente de cuño iberrico, indígena y mesizo, pero conservó sus matnces africanas, no occidentales. Gracias a ello pudieron resistir. En el espacio no controlado de sus cultos vivieron una libertad mínima y se sintieron dignificados al ser portadores, en sus propios cuerpos en trance, de la vida de sus dioses.

¿Qué significa, en este caso, evangelización? Antes que nada, es fundamental que las religiones de los otros sean reconocidas y valoradas, mucho más cuando estos otros fueron dominados y se les negó su propia objetividad. Esto implica reconocer en ellas la presencia, la actuación de Dios, del Espíritu y del Verbo eterno. Tal reconocimiento teologal permite un diálogo de mutuo aprendizaje y de recíproca evangelización. Entonces, la evangelización significa el descubrimiento progresivo que se hace de la revelación divina en las religiones y el mensaje que comporta para todos, no solamente para las respectivas culturas. Las religiones nos ayudan a comprender y a amar más profundamente el misterio de comunión del Dios de la historia.

La mutua apertura permite una evangelización urgente de la Iglesia. Esta intenta evangelizar a todos. Pero Łquién evangeliza a la Iglesia? Pablo VI enfatizó en su notable documento sobre la evangelización que "la Iglesia tiene la necesidad de ser evangelizada" (Evangelii Nuntiandi, n. 15). La Iglesia romanocatólica incorporó limitaciones, equivocos y defectos propios de la cultura occidental, como el logocentrismo, el etnocentrismo, que significa la gran dificultad 
de acoger y convivir pacíficamente con las diferencias culturales y religiosas, la forma centralizada y autoritaria del ejercicio del poder, la desconfianza sobre todo lo que es material y corporal, el pauriarcalismo que excluye a las mujeres y que pone bajo sospecha lo femenino, en el hombre y la mujer, y la sexualidad, el individualismo, etc.

Ahora bien, las culturas autóctonas de nuestro continente poseían varios valores comunitarios, de integración del cuerpo, de un ejercicio realmente servicial del poder (como entre los guaranies), de valoración religiosa de la tierra y de la simbologia material, de sencillez y desapego del espíritu de acumulación ${ }^{24}$ que evangelizarian bien a la Iglesia y la harlan más catolica.

En el Coloquio de los doce, lo que los sabios aztecas dicen, objetivamente considerado, tiene más altura teológica y apertura que el discurso de los misioneros europeos. Replican ellos la demonización que sus misioneros habían hecho a sus tradiciones religiosas: "No se impaciente su corazon y su cuerpo, señores nuestros, porque abriremos un poco, un poquito solamente, el secreto, el arca de nuestro Dios. Decían ustedes que no conocemos al Señor que está cercano, que está con nosotros, aquel de quien son los cielos y la lierra. Decían que no eran verdaderos nuestros dioses. Palabra nueva es ésta que nos dicen y con ella nos han turbado. Porque nuestros progenitores, los que existieron, los que vivieron sobre la tierra, no hablaban de esta manera... Y ahora inosotros debemos destruir la antigua regla de vida? ¿La de los chichimecas, la de los toltecas, la de los alcolhuas, la de los tecpanecas? Nosouros sabemos a quién se debe la vida, a quién se debe el nacer, a quiến se debe el engendrar, a quién se debe el crecer, cómo se debe invocar, cómo se debe rogar"zs.

Después, con fino sentido pastoral, cosa que no mostraban la mayoría de los misioneros ibéricos, añaden: "Oigan, señores nuestros, no hagan nada a nuestro pueblo que les traiga desgracia, que les haga perecer... Tranquila y amigablemente consideren, seflores nuestros, lo que es necesario. No podemos estar tranquilos y ciertamente no creemos aún, no lo tomamos por verdad, aunque ello les ofenda... Hagan con nosotros lo que quieran. Esto es todo lo que respondemos, lo que replicamos al ánimo, a su palabra, sefiores nuestros'23.

En el caso que los misioneros se hubiesen dejado evangelizar y si, por ventura, hubiesen vislumbrado, como los primeros pensadores cristianos que entablaron un diálogo profundo con la cultura griega, como Clemente de Alejandría, Justino y Orígenes, viendo allí las semillas del Verbo y la presencia del Espiritu. otro había sido el destino del cristianismo latinoamericano y de las culuras autóclonas. Ciertamente tendrían vigor aquellas culturas y viviríamos un cristianismo con trazos propios de estas culturas, distintos a los europeos. Pero otro fue el camino, de uniformación y de simple duplicado o copia.

La confrontación entre las culturas nos permite percibir también los líniles y 
hasta las patologías que se pueden instalar dentro de las religiones, incluido el cristianismo. Es problemático establecer criterios a partir de los cuales difinir lo que es sano y lo que es patológico. No obstante, creemos que la obra de Dios en las culturas no es de tal suerte confusa e indistinta que no se puede manifestar en su estado saludable como promoción de vida desde la más deteriorada, de comunión, de perdón y de amor. Cuando estas realidades, que pertenecen a lo cotidiano de la existencia, se promueven, podemos decir infaliblemente que Dios y su Espíritu están presentes y actuando.

Evangelizar las culturas autóctonas y afroamericanas implica entrar en un diálogo respetuoso y abierto con ellas. Debe ser llevado con extrema comprensión y empatía, porque nosotros los cristianos tenemos un pasado de injusticias para con todos ellos. Es ya motivo de alegria teologal el hecho de que estas culturas hayan podido subsistir, de que cstén llenas de voluntad de rehacerse biológicamente y de recrearse espiritualmente. El primer acto de evangelización de las Iglesias es promover sus vidas, alentar sus proyectos de rehacer sus culturas, de rescate de sus religiones y de recuperación de sus tiertas. Tal gesto se situia en la línea evangélica de Aquel que dijo tener como misión traer vida y vida en abundancia ( $c f r$. Jn 10,10). Es el evangelio primero, el de la fratemidad universal.

La realización de este tipo de evangelización está aún en los primeros pasos. Los cristianos debemos superar nuestro elnocentrismo cultural y sobre todo nuestra concentración en nuestra propia experiencia de revelación que nos hace amogantes y supuestos detentadores del monopolio de la verdad revelada y de los medios de salvación. Todos estamos en el seno de la verdad y todos podemos crecer en la aproximación y en apropiación personal y colectiva de esa verdad. Según el Jesús de Juan, el Padre quiere ser servido allí donde irrumpe el Espíritu y se vive en la verdad ( $c f r$. Jn 3,25), más allá de las determinaciones históricas (Jerusalén o Garazim). Todos podemos aprender unos de otros acerca de esta verdad y corregir los equívocos y los desaciertos que cometemos contra ella. Esta perspectiva ayudará en la construcción de la paz religiosa, sin la cual tampoco habrá paz social y política entre las naciones.

\section{Estar de parte de las víctimas y en favor de su autonomía y liberación}

Los testimonios emocionantes de los propios indigenas y las reflexiones que hasta aquí aporamos nos muestran la postura más sensata que debemos asumir y apoyar. Debemos comprender todas las posturas, pero no podemos permanecer equidistantes. Es importante asurnir nuestra responsabilidad, fundados en razones convincentes.

No podemos acoger con triunfalismos las celcbraciones de los que hablan de descubrimiento e incorporación del continente a la civilización europea. Sería ofender a millones de víctimas y aumentar su sufrimiento secular. 
Recordemos las palabras proféticas del gran defensor de los derechos de los indios, Bartolomé de las Casas, en su testamento en 1564: "Dios ha de derramar sobre Espafia (y nosotros dirfamos sobre todas las potencias colonizadoras) su furor y su ira, porque toda ella participó en las sangrientas riquezas robadas y tan usurpadas y mal habidas, y con tantos estragos y exterminios de aquellas gentes (los indigenas), si no hace gran penitencia y temo que tarde o nunca lo hara". Si se organizan celebraciones, que sean penitenciales y de profunda revisión de la lógica que presidió la presencia del cristianismo en el continente latinoamericano.

Por razones humanitarias debemos apoyar los esfuerzos de liberación que hist6ricamente siempre fueron atacados. Todo el proceso histórico, social, científico y técnico de los últimos 500 affos no ayudó, sino que marginó aún más a las culturas autóctonas.

Por razones de justicia deben las antiguas potencias coloniales pagar las deudas que contrajeron con las culturas nativas y con los africanos, amancados hasta aqui y esclavizados. Hasta hoy no se les hace la más mínima justicia, pues el proceso del diezmar las culturas y el pillaje de las tierras indigenas avanza avasalladoramente. Hasta el juicio final los indigenas y negros tienen derecho a protestar contra los males a ellos inflingidos y reclamar una condigna reparación. Por eso es importante apoyar los anhelos de liberación y autonomía de las culturas indigenas y afroamericanas, presionar por acuerdos intemacionales que favorezcan a ias naciones empobrecidas por el colonialismo, incluyendo en ello una reparación a los danios ecológicos que cada día se hace más urgente.

Por razones evangélicas debemos asumir las causas y las luchas de aquellos que fueron despojados y hechos injustamente pobres. Ellos son los privilegiados del Dios de la vida que siempre toma partido por aquellos que gritan por la vida y libertad, como los judíos ourora esclavizados en Egipto o exiliados en Babilonia. Si el evangelio es buena noticia de una vida terrenal fraterna y de una vida eterna en comunión con Dios con los humanos y con toda la creación, lo es, ante todo, para ellos. Para ellos tienen validez las bienaventuranzas y las promesas mesiánicas de una liberación integral.

Si la nueva evangelización va a ayudar en esa inmensa tarea de rescate de 500 anos de sudor y de lágrimas, apenas habrá cumplido su deber y pagado un poco la inconmensurable deuda que con ellos contrajimos y de la que aún resta mucho por pagar.

\section{Notas}

1. O que faz o brasil, Brasil, 1986, p. 95-105.

2. Ibid, p.102.

3. Ibid., p.103.

4. Werke 12, Suhrkamp 1970 , p. 108. 
5. De pracuranda indorum salute, o la predicación del evangelio en las Indias, Madrid 1954.

6. Ibid., p. 450.

7. Ibid., p.453.

8. Libro del profeta maya Chilan Balam.

9. Testimonio maya, cf. M. León-Portilla, La conquista de America Latina vista por los indios. Petropolis 1985, p. 61.

10. La visión de los vencidos, LPM. P. Alegre 1987.

11. La vision des vaineus, Gallimard, Paris 1971.

12. Memorias do fogo, 3 vol. Paz e Terra, Rio 1983.

13. L. Portilla, A conquista, op. cir., pp. 30-31.

14. L. Portilla, op. cit., p. 121.

15. L. Portilla, A visao dos vencidos, op., cit. p. 73.

16. L. Portilla, A conquisia, op. cil., p. 41.

17. L. Portilla, op. cu., p. 20.

18. L. Portilla, op. cir. p. 60.

19. L. Portilla, A conquista, op. cil., pp. 100-101.

20. L. Portilla, A conquista, op. cis., p. 62.

21. Dacumento de Puebla, n. 1145.

22. Ver la documentación en el libro editado por el P. Suess, Culturas y evangelización, Loyola, S. Paulo 1991, pp. 239-259.

23. Texto en P. Suess, Culturas y evangelización, op. cir., p. 255.

24. ...que impresionó tanto al mayor etnólogo del siglo XVI, Fray Bernardino de Sahagún en su Historia General de las cosas de Nueva España, 2 vol. Madrid 1988.

25. L. Portilla, A conquista, op. cil., pp. 21-22.

26. Op. cis., pp. 22-23. 